\title{
SIMULASI DAMPAK PENCAHAYAAN RUANG PADA PENGGUNAAN ROSTER SEBAGAI FASAD BANGUNAN
}

\section{Ekky Maulidin}

Prodi Arsitektur Fakultas Teknik

Universitas Muhammadiyah Surakarta

Email : maulidin.ekky@gmail.com

\section{Nurhasan}

Prodi Arsitektur Fakultas Teknik Universitas Muhammadiyah Surakarta Email : nur192@ums.ac.id

\begin{abstract}
ABSTRAK
Penelitian ini berdasarkan kritik terhadap bangunan yang menggunakan roster sebagai desain fasadnya. Tidak sedikit karya-karya arsitek dengan desain serupa bermunculan sebagai tren gaya industrial dengan material ekspos yang lebih ditonjolkan. Mulai beralihnya fungsi roster dari pembatas antar ruang menjadi elemen estetika fasad bangunan perlu dikaji lebih lanjut tentang dampaknya terhadap pencahayaan alami. Sistem pencahayaan pada suatu ruangan sangat dibutuhkan untuk kenyamanan pengguna dalam beraktivitas. Penelitian ini bertujuan mengukur kuat pencahayaan sebagai efek penggunaan roster pada dinding. Metode pengukuran dan simulasi menggunakan software Velux Daylight Visulalizer 2. Simulasi dilakukan dengan mengukur pencahayaan ruang tamu dengan menempatkan beberapa jenis desain roster berbeda, yang umum dijual di pasaran. Nilai kuat cahaya akan dianalisis dan dibandingkan dengan kebutuhan cahaya untuk beraktivitas di ruang tamu. Hasil dari simulasi menyimpulan bahwa cahaya alami tidak dapat mencukupi kebutuhan cahaya ruang sesuai Standar Nasional Indonesia (SNI 03-6197-2000). Oleh karena itu dibutuhkan banyak penyesuaian dari model atau jenis roster untuk fasad. Disain roster yang masih memberikan efek kuat pencahayaan yang belum memenuhi standar, maka dapat diberikan solusi dengan menambah lebih banyak bukaan atau penggunaan sunroof sebagai solusi.
\end{abstract}

KATA KUNCI: arsitek, hunian tropis, industrial, kenyaman ruang, roster

\section{PENDAHULUAN \\ Latar Belakang}

Desain industrial kerap menjadi pilihan karena terkesan sederhana dan ringan. Hal ini dapat dilihat dari penggunaan material fabrikasi yang digunakan seperti roster, beton, dan baja. Roster banyak digunakan karena memberikan tekstur dan kesan modern. Rosterpun sekarang sudah sangat beraneka ragam bentuknya, jenisnya, dan polanya, roster tetap akan terus berkembang seiring dengan berkembangnya desain indutrial itu sendiri, seperti hukum ekonomi sederhana dimana demand and supply akan selalu berusaha selalu melengkapi.

Sebagai manusia yang tinggal dan memiliki rumah di wilayah tropis sudah sewajarnya ada beberapa nilai yang harus dipatuhi guna mendapatkan hasil fungsi yang maksimal. Adapun beberapa fungsi yang harus dapat setidaknya dipenuhi dalam merancang hunian ialah, cahaya, udara, panas dan kelembapan (Lippsmeier, 1994). Hal-hal inilah yang akan coba dipenuhi pada hunian tropis, terlebih apakah penggabungan industrial roster tadi dengan arsitektur tropis sudah menghasilkan kombinasi yang tepat untuk dihuni. Beberapa contoh bangunan yang menggunakan disain roster untuk fasade bangunan dapat dilihat pada gambar 1 .

Bermodalkan hanya teori umum dan rasa, banyak arsitek yang seakan-akan hanya mengikuti arus, membawa nama arsitektur tropis namun hanya sebatas itu saja, padahal di Indonesia sendiri memiliki beragam pendekatan dengan alam di masing-masing daerahnya. Tidak bisa hanya membawa teori luar untuk diterapkan $100 \%$ nya di Indonesia. Tidak bisa juga teori arsitektur tropis secara mentah diterapkan di seluruh hunian di Indonesia. Beberapa daerah perlu perlakuan khusus, dan di situlah peran arsitek tidak hanya sebatas mendesain dan dibayar namun juga mempertimbangkan segala aspek kehidupan agar apa yang didesain memiliki estetika dan fungsi yang selaras. Kerap kali ditemukan di lapangan bahwa hunian yang terkesan bagus, ternyata masih memiliki kekurangan. Peran arsitek harus dapat menyeimbangkan disain yang dibuatnya dengan kondisi Indonesia seutuhnya, agar hunian selaras dengan alam.

Tulisan ini disusun untuk dapat mengemukakan permasalahan utama, yaitu mencari keselarasan antara fungsi dan estetika dalam sebuah bangunan. Pendekatan yang diambil adalah melakukan simulasi 

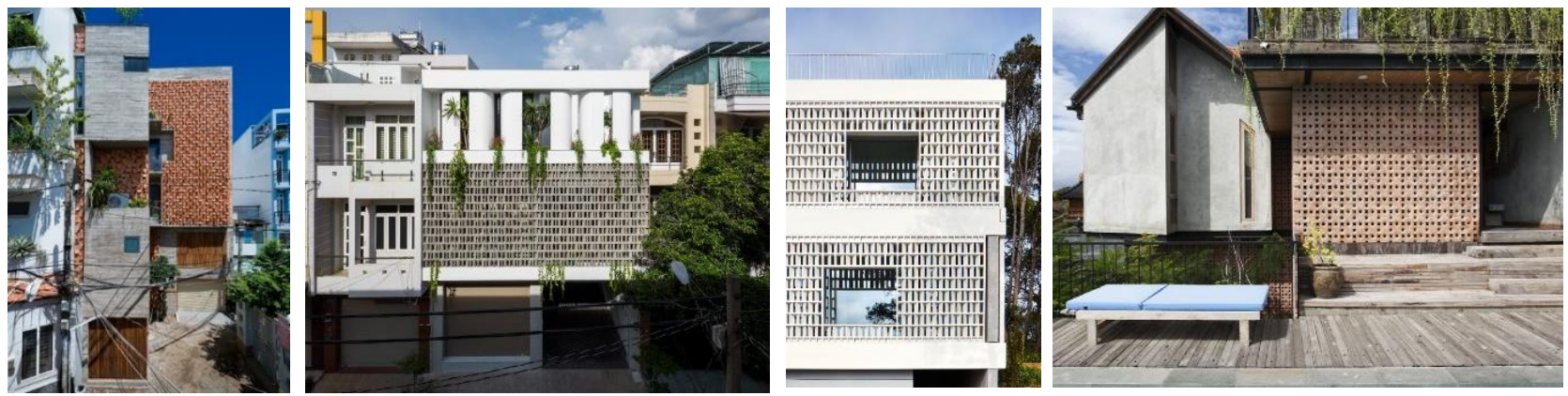

Gambar 1. (a) Chi House (sumber: archdaily.com/774956/chi-house-g-plus-architects), (b) Lien thong house (sumber: archdaily.com/917624/lien-thong-house-6717-studio), (c) Lattice house (Sumber: designboom.com/architecture/lopezrivera-casa-celosia-07-28-18/), (d) Tekuni house (Sumber: archify.com/id/archifynow/ruang-tekuni-pengalaman-

hunian-di-tengah-hutan-tropis)

pencahayaan alami guna mengetahui nilai kombinasi dari salah satu poin arstektur tropis, apakah nilai tersebut dapat terpenuhi untuk dapat dihuni pada sisi pencahayaan yang menjadi satu nilai fungsi absolut bagi hunian di wilayah tropis.

Lingkup cahaya dipilih sebagai batasan penelitian ini karena yang diteliti ialah kuat cahaya sebagai efek penggunaan roster, dan bagaimana hasil penghantaran cahaya dari luar bangunan menuju dalam bangunan. Hasil pengukuran dan simulasi akan memberikan layak dan tidaknya bangunan untuk dihuni sesuai kaidah atau SNI. Selain itu akan memberikan manfaat terhadap pemilihan bentuk roster yang lebih inovatif dan kreatif, agar hunian tidak sekedar indah tapi juga nyaman untuk dihuni.

\section{TINJAUAN PUSTAKA}

\section{Roster}

Merupakan produk dari material bangunan yang terbuat dari campuran semen, pasir, dan air (Darmono, 2012). Berbentuk kubus, dan pada awalnya difungsikan sebagai jalur udara, sehingga di Indonesia pada umumnya diletakan di atas jendela maupun pintu (lihat gambar 2).

Seiring perkembangan jaman, bentuk dan jenis roster beraneka ragam, bahkan ada penyedia roster yang dapat membuat roster jenis pesanan khusus saja, tidak dijual ke pasar bebas.

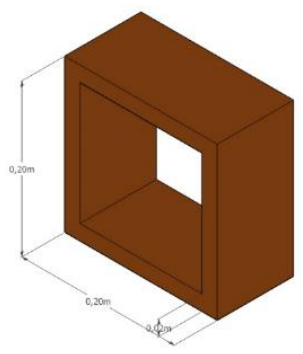

Gambar 2. Bentuk umum roster $20 \times 20 \mathrm{~cm}$ (sumber: adaptasi penulis, 2019)

\section{Arsitektur Tropis}

Arsitektur Tropis adalah suatu konsep bangunan yang mengadaptasi kondisi iklim tropis. Letak geografis
Indonesia yang berada di garis khatulistiwa membuat Indonesia memiliki kelembaban udara yang tinggi dan temperatur udara yang relatif panas sepanjang tahun (Sugiyatmo, 2017). Pada musim kemarau suhu udara sangat tinggi dan sinar matahari memancar sangat panas. Dalam kondisi ikim yang panas inilah muncul ide untuk menyesuaikannya dengan arsitektur bangunan gedung maupun rumah yang dapat memberikan kenyamanan bagi penghuninya, adapun beberapa poin penting yang saling berkaitan di arsitektur tropis ialah:

1. Kenyaman Thermal

2. Aliran Udara

3. Penerangan Alami

\section{Arsitektur Industrial}

Bahwasannya gaya industrial ini lahir pada sekitar tahun 1950an berawal dari banyaknya sisa bangunan pabrik, yang coba dialihfungsikan sebagai hunian pada masa itu. Keadaan ekonomi dan sosial pasca perang pada saat itu serba terbatas, sementara kebutuhan primer harus tetap dipenuhi, maka disiasati suatu konsep bangunan yang baru, dimana minim finishing namun tidak mengurangi fungsi untuk hunian. Pada saat itulah lahir gaya bangunan industrial. Adapun ciri khas bangunan industrial adalah :

1. Penggunakan material bekas

2. Meminimalisasi proses finishing

3. Warna bangunan monokrom

4. Bangunan lebih terekspos

\section{Standar Pencahayaan}

Pencahayan alami yang harus dihasilkan di setiap ruang dalam bangunan, harus memenuhi standar sesuai tabel 1. 
Tabel 1. Standar Pencahayaan Ruang SNI 03-6197-2000

\begin{tabular}{|c|c|c|c|c|c|}
\hline \multirow{2}{*}{$\begin{array}{c}\text { Fungsi } \\
\text { Ruangan }\end{array}$} & \multirow{2}{*}{$\begin{array}{c}\text { Tingkat } \\
\text { Pencahaya } \\
\text { an (lux) }\end{array}$} & \multirow[b]{2}{*}{$\begin{array}{c}\text { Kelom } \\
\text { pok } \\
\text { Renderi } \\
\text { sasi } \\
\text { Warna }\end{array}$} & \multicolumn{3}{|c|}{ Temperatur Warna } \\
\hline & & & $\begin{array}{c}\text { War } \\
m \\
\text { White } \\
<3300 \\
\text { K }\end{array}$ & $\begin{array}{c}\text { Cool } \\
\text { White } \\
3300 \mathrm{~K} \\
- \\
5300 \mathrm{~K}\end{array}$ & $\begin{array}{c}\text { Daylig } \\
\text { ht } \\
>5300 \\
\text { K }\end{array}$ \\
\hline \multicolumn{6}{|l|}{ Rumah Tinggal : } \\
\hline Teras & 60 & 1 atau 2 & $\bullet$ & $\bullet$ & \\
\hline Ruang tamu & $\begin{array}{c}120- \\
150\end{array}$ & 1 atau 2 & & $\bullet$ & \\
\hline Ruang Makan & $\begin{array}{c}120- \\
250\end{array}$ & 1 atau 2 & $\bullet$ & & \\
\hline Ruang Kerja & $\begin{array}{c}120- \\
250\end{array}$ & 1 & & $\bullet$ & $\bullet$ \\
\hline Kamar Tidur & $\begin{array}{c}120- \\
250\end{array}$ & 1 atau 2 & $\bullet$ & $\bullet$ & \\
\hline Kamar Mandi & 250 & 1 atau 2 & & $\bullet$ & $\bullet$ \\
\hline Dapur & 250 & 1 atau 2 & $\bullet$ & $\bullet$ & \\
\hline Garasi & 60 & 3 atau 4 & & $\bullet$ & $\bullet$ \\
\hline \multicolumn{6}{|l|}{ Perkantoran : } \\
\hline $\begin{array}{l}\text { Ruang } \\
\text { Direktur }\end{array}$ & 350 & 1 atau 2 & & $\bullet$ & $\bullet$ \\
\hline Ruang Kerja & 350 & 1 atau 2 & & $\bullet$ & $\bullet$ \\
\hline $\begin{array}{l}\text { Ruang } \\
\text { Komputer }\end{array}$ & 350 & 1 atau 2 & & $\bullet$ & $\bullet$ \\
\hline Ruang Rapat & 300 & 1 & $\bullet$ & $\bullet$ & \\
\hline $\begin{array}{l}\text { Ruang } \\
\text { Gambar }\end{array}$ & 750 & 1 atau 2 & & $\bullet$ & $\bullet$ \\
\hline Gudang Arsip & 150 & 1 atau 2 & & $\bullet$ & $\bullet$ \\
\hline $\begin{array}{l}\text { Ruang Arsip } \\
\text { Aktif }\end{array}$ & 300 & 1 atau 2 & & $\bullet$ & $\bullet$ \\
\hline \multicolumn{6}{|c|}{ Lembaga Pendidikan : } \\
\hline Ruang Kelas & 250 & 1 atau 2 & & $\bullet$ & $\bullet$ \\
\hline Perpustakaan & 300 & 1 atau 2 & & $\bullet$ & $\bullet$ \\
\hline Laboratorium & 500 & 1 & & $\bullet$ & $\bullet$ \\
\hline Ruang Gambar & 750 & 1 & & $\bullet$ & $\bullet$ \\
\hline Kantin & 200 & 1 & $\bullet$ & $\bullet$ & \\
\hline \multicolumn{6}{|c|}{ Hotel dan Restauran : } \\
\hline Lobi, Koridor & 100 & 1 & $\bullet$ & $\bullet$ & \\
\hline $\begin{array}{l}\text { Ruang Serba } \\
\text { Guna }\end{array}$ & 200 & 1 & $\bullet$ & $\bullet$ & \\
\hline Ruang Makan & 250 & 1 & $\bullet$ & $\bullet$ & \\
\hline Kafetaria & 200 & 1 & $\bullet$ & $\bullet$ & \\
\hline Kamar Tidur & 150 & 1 atau 2 & $\bullet$ & & \\
\hline Dapur & 300 & 1 & $\bullet$ & $\bullet$ & \\
\hline \multicolumn{6}{|l|}{ Rumah Sakit : } \\
\hline $\begin{array}{l}\text { Ruang Rawat } \\
\text { Inap }\end{array}$ & 250 & 1 atau 2 & & $\bullet$ & $\bullet$ \\
\hline Ruang Operasi & 300 & 1 & & $\bullet$ & $\bullet$ \\
\hline laboratorium & 500 & 1 atau 2 & & $\bullet$ & $\bullet$ \\
\hline $\begin{array}{l}\text { Ruang } \\
\text { Reklreasi }\end{array}$ & 250 & 1 & $\bullet$ & $\bullet$ & \\
\hline \multicolumn{6}{|c|}{ Pertokoan / Ruang Pamer : } \\
\hline $\begin{array}{l}\text { Ruang Pamer } \\
\text { Besar }\end{array}$ & 500 & 1 & $\bullet$ & $\bullet$ & $\bullet$ \\
\hline $\begin{array}{l}\text { Toko Kue dan } \\
\text { Makanan }\end{array}$ & 250 & 1 & $\bullet$ & $\bullet$ & \\
\hline Toko Bunga & 250 & 1 & $\bullet$ & $\bullet$ & \\
\hline $\begin{array}{l}\text { Toko Buku dan } \\
\text { Alat, Tulis, } \\
\text { Gambar }\end{array}$ & 300 & 1 & $\bullet$ & $\bullet$ & $\bullet$ \\
\hline $\begin{array}{l}\text { Toko } \\
\text { Perhiasan, } \\
\text { Arloji }\end{array}$ & 500 & 1 & $\bullet$ & $\bullet$ & \\
\hline $\begin{array}{l}\text { Toko Barang } \\
\text { Kulit dan } \\
\text { Sepatu }\end{array}$ & 500 & 1 & $\bullet$ & $\bullet$ & \\
\hline Toko Pakaian & 500 & 1 & $\bullet$ & $\bullet$ & \\
\hline Pasar Swalayan & 500 & 1 atau 2 & $\bullet$ & $\bullet$ & \\
\hline
\end{tabular}

\begin{tabular}{|c|c|c|c|c|c|}
\hline $\begin{array}{c}\text { Fungsi } \\
\text { Ruangan }\end{array}$ & $\begin{array}{c}\text { Tingkat } \\
\text { Pencahaya } \\
\text { an (lux) }\end{array}$ & $\begin{array}{c}\text { Kelom } \\
\text { pok } \\
\text { Renderi } \\
\text { sasi } \\
\text { Warna }\end{array}$ & $\begin{array}{c}\text { Tem } \\
\text { War } \\
\text { m } \\
\text { White } \\
<3300 \\
\text { K }\end{array}$ & $\begin{array}{c}\text { eratur } \\
\text { Cool } \\
\text { White } \\
3300 \mathrm{~K} \\
- \\
5300 \mathrm{~K}\end{array}$ & $\begin{array}{c}\text { Iarna } \\
\text { Daylig } \\
\text { ht } \\
>5300 \\
\text { K }\end{array}$ \\
\hline Toko Mainan & 500 & 1 & $\bullet$ & $\bullet$ & \\
\hline $\begin{array}{l}\text { Toko Alat } \\
\text { Listrik }\end{array}$ & 250 & 1 atau 2 & $\bullet$ & $\bullet$ & $\bullet$ \\
\hline $\begin{array}{l}\text { Toko Alat } \\
\text { Musik }\end{array}$ & 250 & 1 & $\bullet$ & $\bullet$ & $\bullet$ \\
\hline \multicolumn{6}{|c|}{ Industri (Umum) : } \\
\hline Gudang & 100 & 3 & & $\bullet$ & $\bullet$ \\
\hline Pekerja Kasar & $\begin{array}{c}100- \\
200\end{array}$ & 2 atau 3 & & $\bullet$ & $\bullet$ \\
\hline $\begin{array}{l}\text { PekerjaMenen } \\
\text { gah }\end{array}$ & $\begin{array}{c}200- \\
500\end{array}$ & 1 atau 2 & & $\bullet$ & $\bullet$ \\
\hline Pekerja Halus & $\begin{array}{l}500- \\
1000\end{array}$ & 1 & & $\bullet$ & $\bullet$ \\
\hline $\begin{array}{l}\text { Pekerja Amat } \\
\text { Halus }\end{array}$ & $\begin{array}{c}1000- \\
2000\end{array}$ & 1 & & $\bullet$ & $\bullet$ \\
\hline $\begin{array}{l}\text { Pemeriksaan } \\
\text { Warna }\end{array}$ & 750 & 1 & & $\bullet$ & $\bullet$ \\
\hline \multicolumn{6}{|l|}{ Rumah Ibadah : } \\
\hline Masjid & 200 & 1 atau 2 & & $\bullet$ & \\
\hline Gereja & 200 & 1 atau 2 & & $\bullet$ & \\
\hline Vihara & 200 & 1 atau 2 & & $\bullet$ & \\
\hline
\end{tabular}

\section{METODE PENELITIAN}

Metode penelitian yang digunakan ialah kuantitatif dimana pengukuran kuat cahaya dilakukan berkali kali dengan kondisi yang sama dan metode yang sama. Simulasi dilakukan dengan mengukur jenis tipe roster yang berbeda-beda pada ruang yang sama yaitu ruang tamu. Data nilai dilakukan berulang dari tiap simulasi hasilnya nilai tersebut akan disandingkan sehingga timbul perbedaan yang dapat dijadikan acuan kesimpulan dan saran.

Fokus penelitian ini dibatasi pada panjang rambat cahaya pada suatu ruang jika fasadnya menggunakan roster yang dijadikan sampel penelitian, dengan mempertimbangkan pula arah bangunan dan waktu Adapun peralatan yang digunakan selama penelitian ialah sebagai berikut :
1. Laptop
2. Alat tulis
3. Kamera

\section{HASIL DAN PEMBAHASAN}

Identifikasi jenis roster

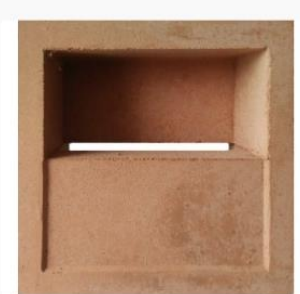

TIPE 1 ROSTER JALOSI

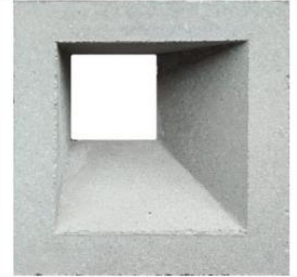

TIPE $2^{\text {ROSTER B1 SUDUR }}$ 


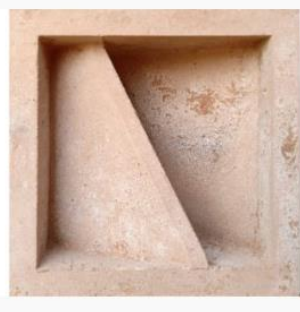

TIPE 3

ROSTER MNC A

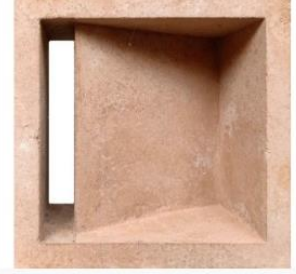

TIPE 4 ROSTER B1 MURNI

External Walls

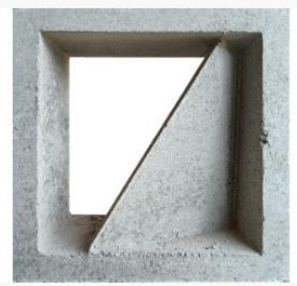

TIPE 5 ROSTER MNCD
Gambar 3. Jenis roster untuk simulasi

Identifikasi ruang simulasi

Pada tahap ini ruang simulasi yang digunakan ialah rumah atau hunian tempat tinggal. Simulasi menggunakan software velux daylight visulalizer 2 . Software ini merupakan perangkat lunak yang umum digunakan untuk melakukan analisis pencahayaan alami maupun buatan. Pada penggunaan simulasi ini digunakan sketchup terlebih dahulu untuk membuat model visual 3 dimensi rumah yang menyerupai hunian yang kondisi aslinya menggunakan roster sebagai fasad muka bangunannya. Adapun jenis dan model roster yang disimulasikan seperti pada gambar 3 , sedangkan rumah tinggal (asli) yang dijadikan model simulasi ada pada gambar 4, sedangkan visualisasi melalui sketch-up sesuai bentuk aslinya, untuk siap disimulasikan seperti pada gambar 5 .
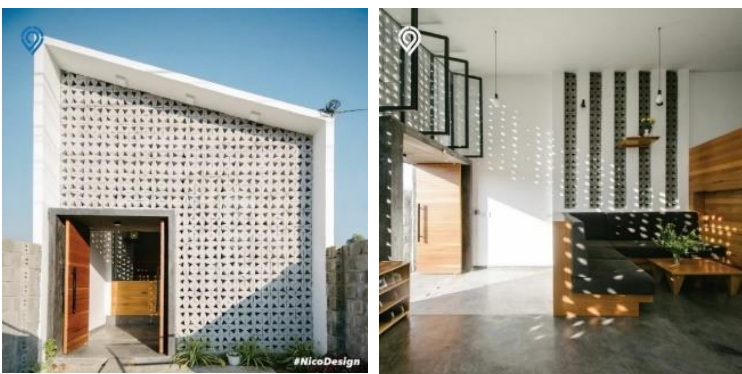

Gambar 4. Khuon studio, tampak depan dan Interior (Sumber: Archdaily.com)
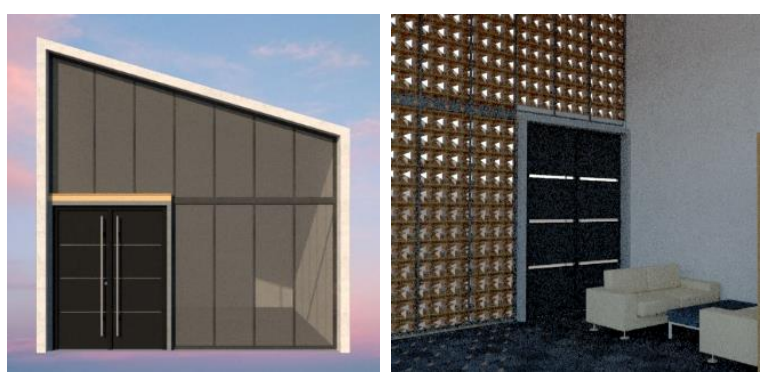

Gambar 5. Visualisasi exterior ke 3 dimensi (sumber: adaptasi penulis, 2019)
Model ruang tamu, terdiri dari dua buah kursi sofa dan satu meja, selanjutnya mengisi tingkat serap cahaya dan pantul tiap-tiap material dengan kriteria default untuk setiap proses pencarian data ialah sebagai berikut :

$\begin{array}{lll}\text { Exterior Ground } & \rightarrow & \text { Grass } \\ \text { O136 Charoal } & \rightarrow & \text { Stone Tiles 2 } \\ \text { <gray> } & \rightarrow & \text { Concrete } \\ \text { Alumunium } & \rightarrow & \text { Alumunium } \\ \text { Blacktop Old } & \rightarrow & \text { Concrete } \\ \text { Colour 008 } & \rightarrow & \text { Stone Tiles 2 } \\ \text { Default } & \rightarrow & \text { Concrete } \\ \text { M. Alumunium } & \rightarrow & \text { Alumunium } \\ \text { M. Corrogated } & \rightarrow & \text { Steel } \\ \text { Polish C.New } & \rightarrow & \text { Concrete } \\ \text { Polish C.Old } & \rightarrow & \text { Concrete } \\ \text { Slate Light tile } & \rightarrow & \text { Stone Tiles 2 } \\ \text { T. Glass G } & \rightarrow & \text { 78\% translucent } \\ \text { Wallpaper } & \rightarrow & \text { Beige Matt }\end{array}$

Identifikasi pencahayaan simulasi

Pada proses ini disimulasikan berbagai kemungkinan cahaya alami yang ada, berikut arah mata angin, waktu (pagi, siang, dan sore). Simulasi dilakukan pada bulan Agustus dengan keadaan cerah dan juga sampel jumlah lux interior pada hasil analisis yang dianggap tertinggi cahayanya sebagai data pada masing masing jenis roster yang ada (koordinat $7^{\circ} \mathrm{S}, 110^{\circ} \mathrm{E}$ ). Hasil pengukuran kuat pencahayaan/penerangan efek roster dari berbagai jenis terlihat dalam tabel 2-7, dan simulasi distribusi cahaya ada dalam gambar 6-17.

Tabel 2. Ruang tamu (Kaca)

\begin{tabular}{|c|c|c|c|c|}
\hline $\begin{array}{l}\text { JAM } \\
\text { SUMBU }\end{array}$ & $0^{\circ}$ & $90^{\circ}$ & $180^{\circ}$ & $270^{\circ}$ \\
\hline PAGI & 259,7 & 830,6 & 659,2 Lux & 242,3 \\
\hline 08.00 & Lux & Lux & & Lux \\
\hline SIANG & 464,1 & 625,7 & 1025,25 & 637 Lux \\
\hline 12.00 & Lux & Lux & Lux & \\
\hline SORE & 265,6 & 241,4 & 446,1 Lux & 814,7 \\
\hline 16.00 & Lux & Lux & & Lux \\
\hline
\end{tabular}

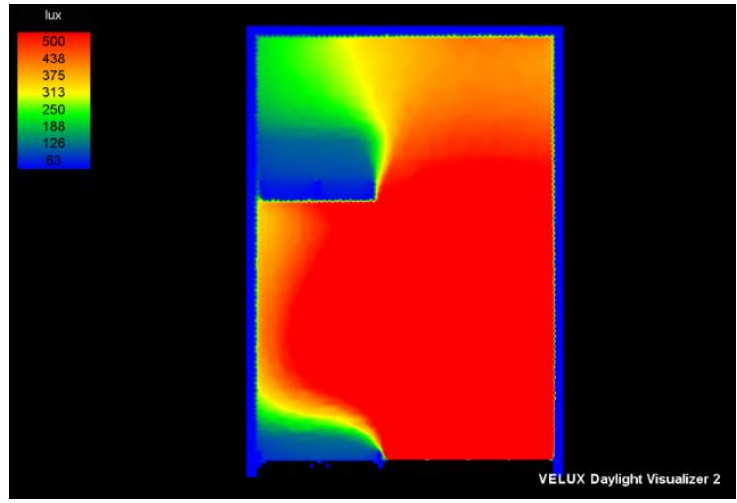

Gambar 6. Visualisasi denah sore 16.00 sudut $270^{\circ}$

SINEKTIKA Jurnal Arsitektur, Vol. 16, No 1 Januari 2019 | 


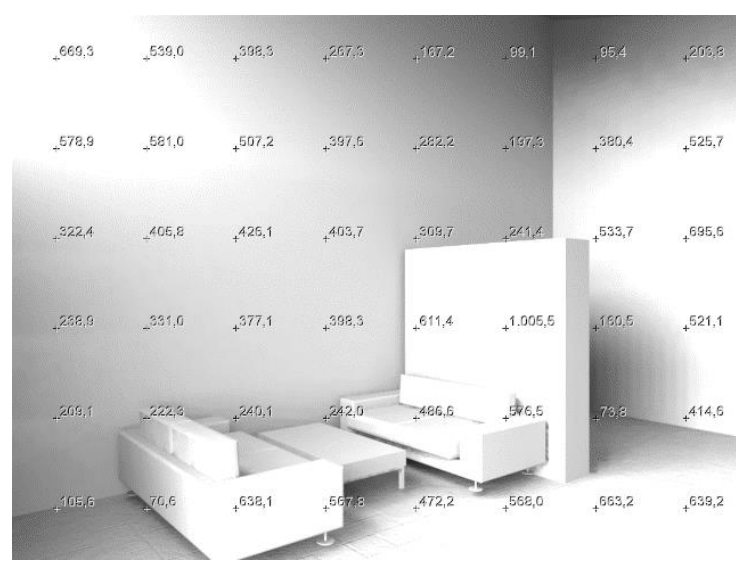

Gambar 7. Visualisasi interior sore 16.00 sudut $270^{\circ}$

Roster berjenis kaca menghasilkan kuat penerangan yang tinggi, baik pagi, siang dan sore hari. Nilai lux yang terlampau tinggi mencapai 1025,25 Lux, membuat silau dan cenderung terasa panas.

Gambar 6 menunjukkan simulasi dengan distribusi cahaya merata ke seluruh bagian ruang, kecuali dekat furniture. Penyebaran cahaya ruang tidak dapat ditoleran nilai kenyamanannya.

Tabel 3. Ruang tamu (Roster tipe1-Jalosi)

\begin{tabular}{|c|c|c|c|c|}
\hline $\begin{array}{l}\text { JAM } \\
\text { SUMBU }\end{array}$ & $0^{\circ}$ & $90^{\circ}$ & $180^{\circ}$ & $270^{\circ}$ \\
\hline PAGI 08.00 & 6,9 Lux & $\begin{array}{l}23,2 \\
\text { Lux }\end{array}$ & 9,2 Lux & 6,7 Lux \\
\hline SIANG & 12,9 & 15,4 & 25,2 & 15,5 \\
\hline 12.00 & Lux & Lux & Lux & Lux \\
\hline SORE 16.00 & 6,9 Lux & 6,6 Lux & $\begin{array}{l}11,8 \\
\text { Lux }\end{array}$ & $\begin{array}{l}21,6 \\
\text { Lux }\end{array}$ \\
\hline
\end{tabular}

Cahaya yang dapat merambat masuk ke dalam ruang terhitung sangat rendah, dan itu cenderung gelap dan tidak layak huni (gambar 8). Penyebab keadaan cenderung gelap karena roster tipe Jalosi memiliki bukaan yang sangat sedikit dan disain lubang cahaya cenderung memasukkan cahaya tidak secara frontal dari depan, namun cahaya masuk dari arah atas atau bawah. Lubang roster lebih tertutup dari arah depan, sehingga lubang roster tidak dapat menangkap cahaya dengan mudah, dan cahaya tidak bisa masuk ruang secara langsung.

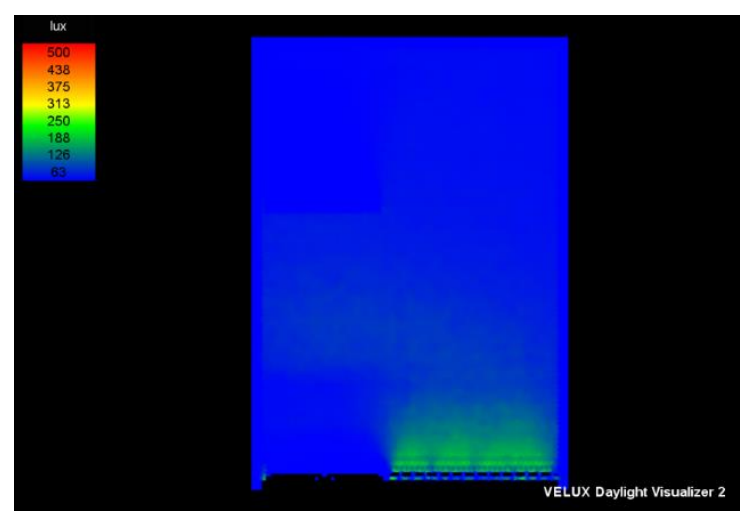

Gambar 8. Visualisasi denah siang 12.00 sudut $180^{\circ}$

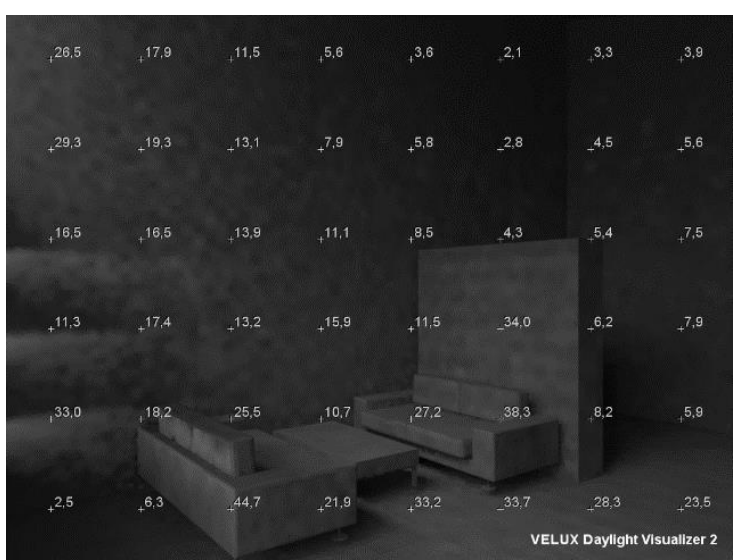

Gambar 9. Visualisasi interior siang 12.00 sudut $180^{\circ}$

Tabel 4. Ruang tamu (Roster tipe2-B1 Sudur)

\begin{tabular}{ccccc}
\hline $\begin{array}{c}\text { JAM } \\
\text { SUMBU }\end{array}$ & $\mathbf{0}^{\circ}$ & $\mathbf{9 0}^{\circ}$ & $\mathbf{1 8 0}^{\circ}$ & $\mathbf{2 7 0 ^ { \circ }}$ \\
\hline PAGI 08.00 & 2,9 Lux & 8,5 Lux & 4 Lux & 2,7 Lux \\
\hline SIANG 12.00 & 4,7 Lux & 6,2 Lux & 7,8 Lux & 5,8 Lux \\
\hline SORE 16.00 & 2,6 Lux & 2,6 Lux & 4,7 Lux & 7,2 Lux
\end{tabular}

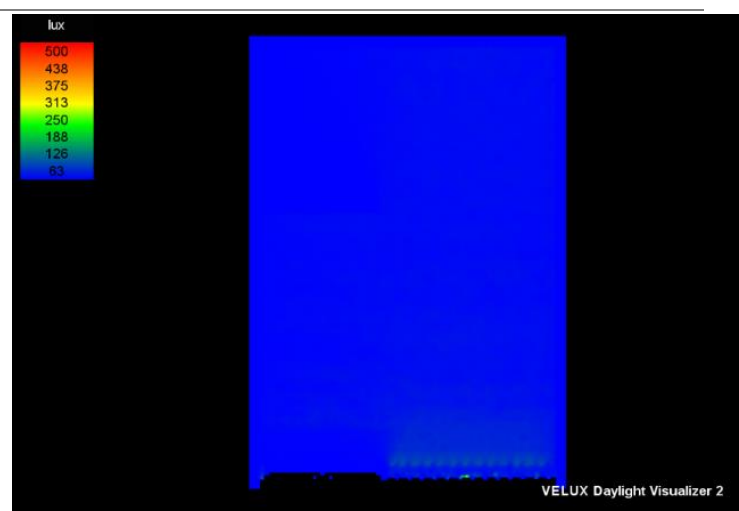

Gambar 10. Visualisasi denah siang 16.00 sudut $270^{\circ}$

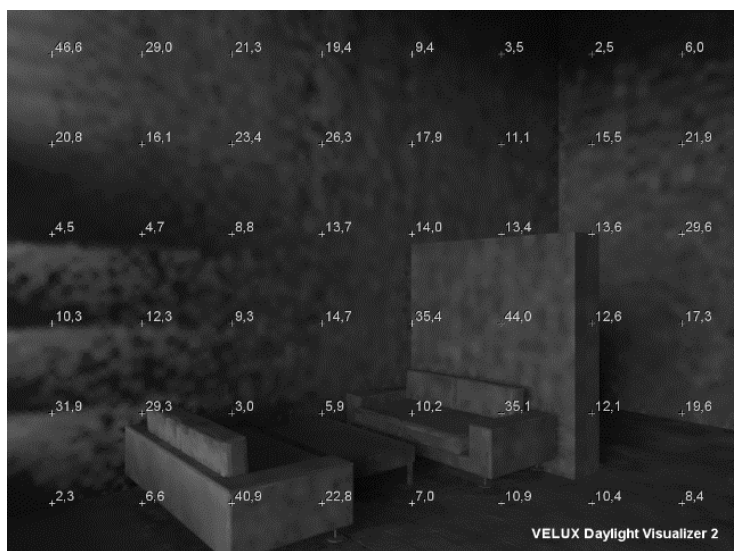

Gambar 11. Visualisasi interior siang 16.00 sudut $270^{\circ}$

Roster tipe 2-B1 Sudur memberikan efek ruang menjadi gelap, lebih gelap dari efek penggunaan roster Jalosi. Karakteristik bentuk roster tipe B1 Sudur sebetulnya memiliki lubang cahaya lebih besar dari tipe Jalosi, namun bentuk lubang sisi luar dan sisi 
dalam berbeda. Lubang di sisi luar lebih besar daripada lubang siis dalam, sehingga bentuk seolah mengerucut ke dalam. Bentuk roster B1-Sudur sama halnya dengan roster tipe Jalosi, sama-sama lebih memberikan fungsi menghindari tampias air hujan, dari pada efek kuat penerangan yang cukup.

Roster berikutnya adalah tipe 3 roster MNC-A. Lubang cahaya pada jenis roster ini posisi miring dan tidak tampak secara frontal. Tipe 3 ini memberikan efek semakin gelap atau paling tidak sama dengan tipe 2 B1-Sudur, sebagaimana dapat dilihat dalam tabel 5 hasil pengukuran kuat penerangannya. Simulasi roster tipe 3 ini ternyata sedikit efek cahaya masuk, walaupun sedikit.

Tabel 5. Ruang tamu (Roster tipe3-MNC-A)

\begin{tabular}{|c|c|c|c|c|}
\hline $\begin{array}{c}\text { JAM } \\
\text { SUMBU }\end{array}$ & $0^{\circ}$ & $90^{\circ}$ & $180^{\circ}$ & $270^{\circ}$ \\
\hline PAGI 08.00 & 6,8 Lux & $\begin{array}{l}23,8 \\
\text { Lux }\end{array}$ & $\begin{array}{l}10,7 \\
\text { Lux }\end{array}$ & 6,3 Lux \\
\hline $\begin{array}{l}\text { SIANG } \\
12.00\end{array}$ & $\begin{array}{l}13,3 \\
\text { Lux }\end{array}$ & 18 Lux & $\begin{array}{l}34,9 \\
\text { Lux }\end{array}$ & 18 Lux \\
\hline SORE 16.00 & 6,8 Lux & 6,4 Lux & $\begin{array}{l}10,9 \\
\text { Lux }\end{array}$ & $\begin{array}{l}23,1 \\
\text { Lux }\end{array}$ \\
\hline
\end{tabular}

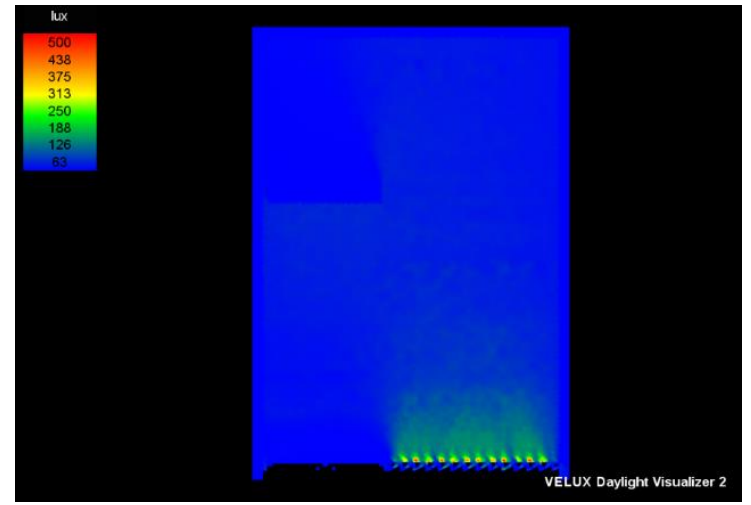

Gambar 12. Visualisasi denah siang 08.00 sudut $90^{\circ}$

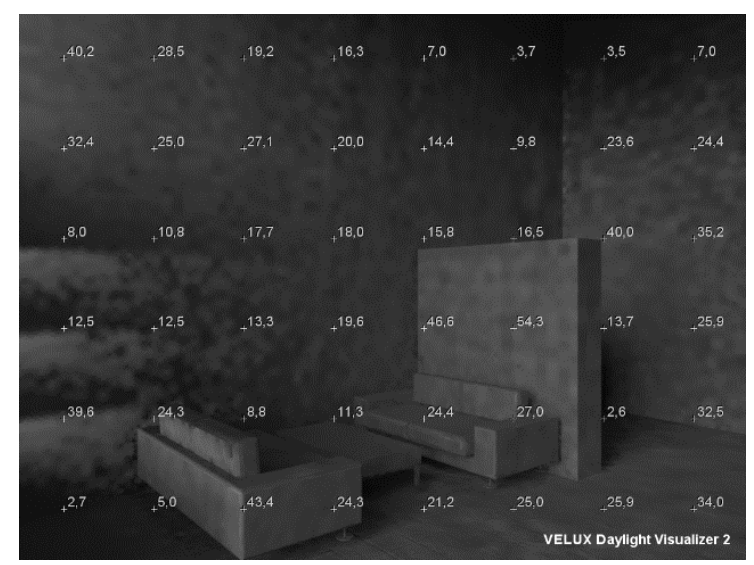

Gambar 13. Visualisasi interior siang 08.00 sudut $90^{\circ}$
Gambar 12 visualisasi efek roster tipe 3 MNC-A, yang sedikit memasukkan cahaya pagi. Sudut cahaya pagi hari di bulan Agustus, dimana matahari berada di sisi utara, ternyata memberikan sedikit perubahan nilai kuat penerangan di bagian ruang yang berdekatan dengan posisi dinding roster. Ada guratan cahaya memasuki ruang, namun tidak sampai menerangi ruang.

Roster tipe 4 adalah roster tipe B1-Murni. Karakteristik roster ini hampir sama dengan tipe 3 MNC-A, hanya saja pada bagian sisi dalam tidak terdapat bidang penghalang. Hasil pengukuran kuat penerangan memperlihatkan nilai yang rendah, artinya efek gelap yang muncul dari penggunaan roster ini. Apabila akan disesuaikan dengan persyaratan kuat cahaya di ruang tamu, dengan standar SNI adalah 150-200 lux, maka akan sangat jauh untuk mencapai standar tersebut.

Tabel 6. Ruang tamu (Roster tipe 4-B1 Murni)

\begin{tabular}{|c|c|c|c|c|}
\hline $\begin{array}{l}\text { JAM } \\
\quad \text { SUMBU }\end{array}$ & $0^{\circ}$ & $90^{\circ}$ & $180^{\circ}$ & $270^{\circ}$ \\
\hline PAGI 08.00 & 4,4 Lux & 11,1 Lux & 6,7 Lux & 4,3 Lux \\
\hline SIANG 12.00 & 8,6 Lux & 9,8 Lux & 14,4 Lux & 10 Lux \\
\hline SORE 16.00 & 4,5 Lux & 4,2 Lux & 6,3 Lux & 12,5 Lux \\
\hline
\end{tabular}

menyesuaikan dengan karakteristik roster dan waktu. Pagi hari jam 08.00, dimana cahaya matahari belum begitu tinggi, namun cahaya tidak dapat masuk secara maksimal, disebabkan bentuk lubang pada roster tersebut.

Cahaya yang dapat merambat masuk ke dalam ruang terhitung sangat rendah, dan ruang cenderung gelap. Hal ini hampir sama seperti roster tipe 2 B1Sudur, bahwa dalam keadaan terbaik pun, dimana siang hari yang kuat cahayanya tinggi, ternyata cahaya yang masuk ke dalam ruang tamu pun masih sangat minim.

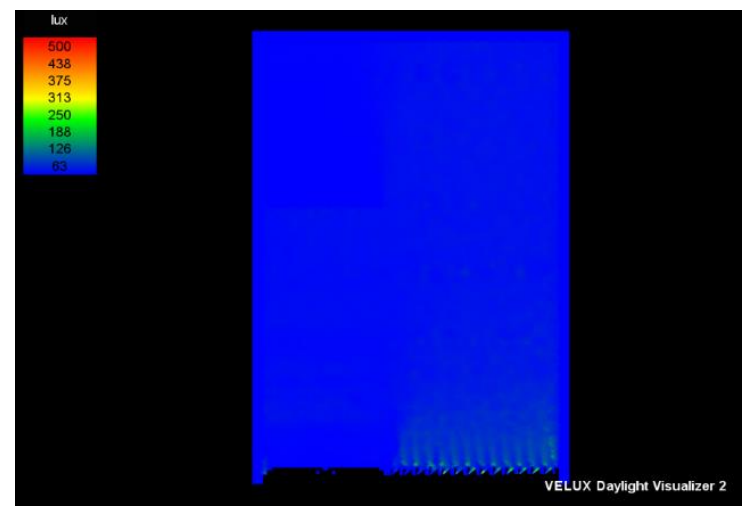

Gambar 14. Visualisasi denah siang 08.00 sudut $90^{\circ}$

Gambar 14 memperlihatkan cahaya alami yang masuk ke dalam ruang sangat sedikit sekali, bahkan ruang cenderung gelap, seperti ditunjukkan gambar 15.

SINEKTIKA Jurnal Arsitektur, Vol. 16, No 1 Januari 2019 


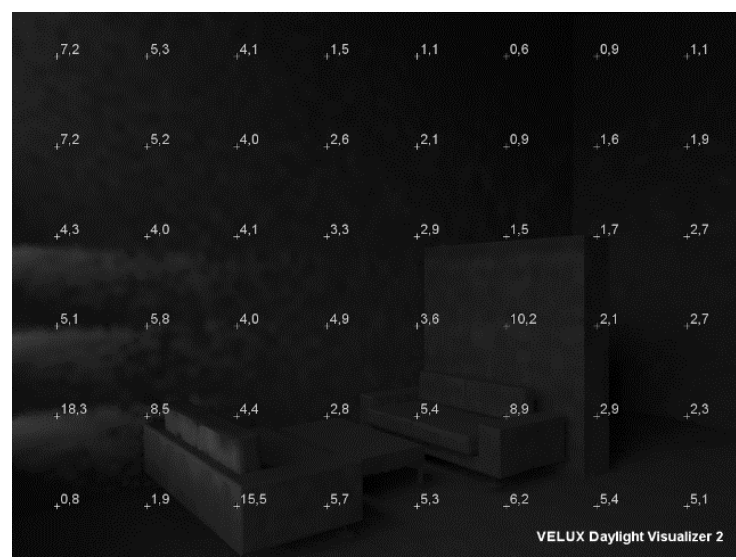

Gambar 15. Visualisasi interior siang 08.00 sudut $90^{\circ}$

Roster berikutnya adalah tipe 5, yaitu roster tipe MNC-D, dengan hasil pengukuran seperti tabel 7.

Tabel 7. Ruang tamu (Roster tipe 5-MNC-D)

\begin{tabular}{ccccc}
\hline $\begin{array}{c}\text { JAM } \\
\text { SUMBU }\end{array}$ & $\mathbf{0}^{\circ}$ & $\mathbf{9 0}^{\circ}$ & $\mathbf{1 8 0}^{\circ}$ & $\mathbf{2 7 0}^{\circ}$ \\
\hline PAGI 08.00 & $\begin{array}{c}19,2 \\
\text { Lux }\end{array}$ & $\begin{array}{c}65,6 \\
\text { Lux }\end{array}$ & $\begin{array}{c}25,5 \\
\text { Lux }\end{array}$ & $\begin{array}{c}18,5 \\
\text { Lux }\end{array}$ \\
\hline SIANG & 33,4 & 41 Lux & 62,3 & $\begin{array}{c}39,5 \\
\text { Lux }\end{array}$ \\
12.00 & Lux & & Lux \\
\hline SORE 16.00 & 18,4 & 18,3 & 32 Lux & $\begin{array}{c}60,9 \\
\text { Lux }\end{array}$ \\
& Lux & Lux & & Lux \\
\hline
\end{tabular}

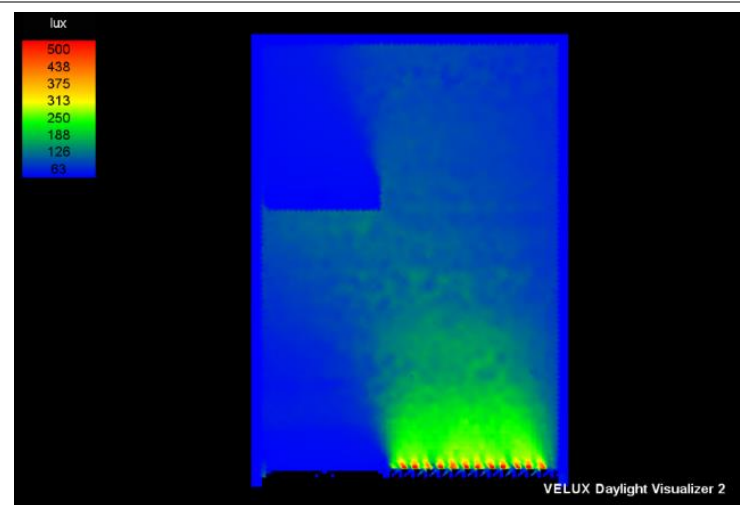

Gambar 16. Visualisasi interior siang 08.00 sudut $90^{\circ}$

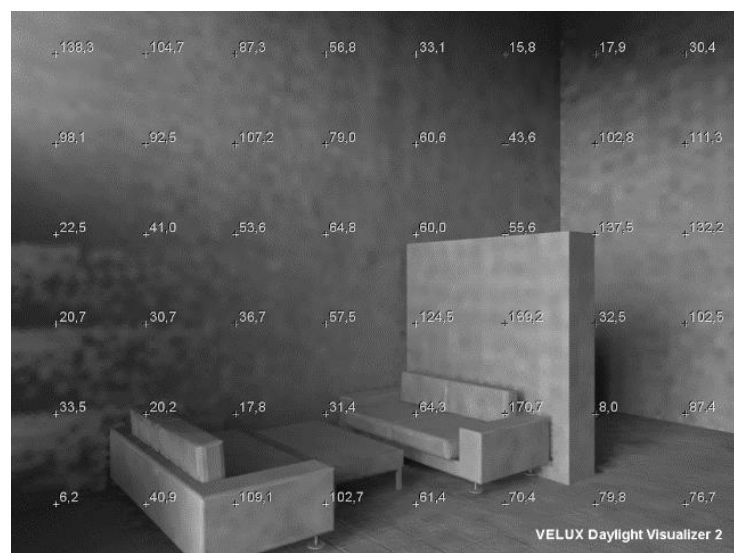

Gambar 17. Visualisasi interior siang 08.00 sudut $90^{\circ}$
Roster tipe 5 yaitu roster MNC-D, dimana bentuknya memiliki lubang cahaya yang lebih besar. Hasil pengukuran membuktikan perolehan nilai kuat penerangan lebih baik dari tipe roster sebelumnya. Cukup ada perbedaan pada tipe 5 ini, dengan bukaan yang lebih lebar pula cahaya dapat lebih banyak masuk meskipun masih tergolong rendah dari standar SNI 036197-2000yang telah ditentukan. Hasil simulasi roster tipe 5 ini adalah lebih memperlihatkan cahaya masuk lebih terdistribusi dengan baik, walapun belum maksimal menerangi seluruh bagian ruang.

Dapat dilihat perubahan masing-masing cahaya ruang, bahwa pada setiap roster dengan jenis berbeda didapat hasil yang kurang lebih sama, bahwa cahaya yang masuk bisa sangat rendah bahkan sudah pada waktu terbaik hasilnya juga sama.

\section{KESIMPULAN}

Serangkaian proses penelitian pengukuran kuat penerangan ini menunjukan hasil dimana roster sebagai fasad bangunan kurang dirasakan manfaat dari segi pencahayaan alaminya. Karakteristik roster merupakan dinding bernafas, sehingga penggunaan roster secara massive di muka bangunan mungkin akan terkesan bagus namun di satu sisi estetika harus bisa berjalan lurus dengan fungsi. Roster sebetulnya memiliki fungsi penyaring cahaya alami, sebagai salah satu mekanisme dalam memanfaatkan cahaya alami.

Upaya menempatkan roster sebagai solusi pada konsep arsitektur tropis, dimana berharap udara dapat bergerak bebas mengisi ruang atau rumah sekaligus cahaya dapat masuk ruang dengan leluasa pula, ternyata tidak sesuai harapan. Bentuk roster tertentu akan menekan jumlah cahaya alami untuk masuk ruang.

Perbandingan lima tipe roster dengan bukaan yang berbeda-beda hasil yang didapat tidak jauh berbeda. Oleh sebab itu jika tren bangunan industrial di wilayah tropis ini tetap berlanjut maka diharuskan adanya pengembangan material bangunan yang baru, terutama mencari titik keseimbangan antara masuk cahaya dan udara guna menciptakan hunian yang nyaman dan humanis. Diharapkan penelitian ini dapat terus berkembang guna menemukan tatanan dan kaidah serta memperbaiki apa yang sebenarnya melenceng pada dunia perancangan arsitektur.

\section{UCAPAN TERIMA KASIH}

Terima kasih banyak kepada dosen dan semua teman teman yang telah memberikan beberapa masukan guna menyempurnakan hasil penelitian ini menjadi suatu data yang valid dan bermanfaat dapat digunakan sebagai referensi. 


\section{DAFTAR PUSTAKA}

Darmono. 2012.Teknologi Pembuatan Bahan Bangunan Berbahan Pasir (Batako) Hasil Erupsi Merapi Di Lereng Bagian Utara, Jurnal Inotek Vol 16 No 1 Februari 2012, p. 78-81.

Lippsmeier, Georg. 1994. Bangunan Tropis. Jakarta. penerbit Erlangga

SNI 03-6197-2000. Konservasi Energi Pada Sistem Pencahayaan. Badan Standarisasi Indonesial

Sugiyatmo, DR, Ir, RM., 2017. Pengertian dan Konsep Arsitektur Tropis. [Online] Available at: http://trtb.pemkomedan.go.id/artikel-963teknik-struktur- bangunan-dengan-konstruksikayu.html [Diakses 12 Desember 2018].

https://www.arsitag.com/article/konsep-desainarsitektur-industrial Diakses Pada Tanggal (7 Desember 2018).

http://trtb.pemkomedan.go.id/artikel-963pengertian-dan-konsep-arsitektur-tropis.html\#ixzz69fU30ki3 [diakses 12 Desember 2018]

https://www.archdaily.com/774956/chi-house-gplus-architects [diakses 12 Desember 2018]

https://www.archdaily.com/917624/lien-thonghouse-6717-studio [diakses 12 Desember 2018]

https://www.designboom.com/architecture/lopezrivera-casa-celosia-07-28-18/ [diakses 12 Desember 2018]

https://www.archify.com/id/archifynow/ruangtekuni-pengalaman-hunian-di-tengah-hutantropis [diakses 12 Desember 2018] 